\title{
Determination of sea surface height from moving ships with dynamic corrections
} Research Article

\author{
J. Reinking ${ }^{1 *}$, A. Härting ${ }^{2}$ and L. Bastos ${ }^{3,4}$
}

1 Department of Geoinformation, Jade University of Applied Sciences, Ofener Str. 16, 26121, Oldenburg, Germany

2 Department of Maritime Studies, Jade University of Applied Sciences, Elsfleth, Germany

3 Centro Interdisciplinar de Investigação Marinha e Ambiental, Universidade do Porto, Portugal

4 Departamento de Geociências Ambiente e Ordenamento do Território, Faculdade de Ciências, Universidade do Porto, Portugal

\begin{abstract}
:
With the growing global efforts to estimate the influence of civilization on the climate change it would be desirable to survey sea surface heights (SSH) not only by remote sensing techniques like satellite altimetry or (GNSS) Global Navigation Satellite System reflectometry but also by direct and in-situ measurements in the open ocean. In recent years different groups attempted to determine SSH by ship-based GNSS observations. Due to recent advances in kinematic GNSS (PPP) Precise Point Positioning analysis it is already possible to derive GNSS antenna heights with a quality of a few centimeters. Therefore it is foreseeable that this technique will be used more intensively in the future, with obvious advantages in sea positioning. For the determination of actual SSH from GNSS-derived antenna heights aboard seagoing vessels some essential hydrostatic and hydrodynamic corrections must be considered in addition to ocean dynamics and related corrections. Systematic influences of ship dynamics were intensively analyzed and sophisticated techniques were developed at the Jade University during the last decades to precisely estimate mandatory corrections. In this paper we will describe the required analyses and demonstrate their application by presenting a case study from an experiment on a cruise vessel carried out in March 2011 in the Atlantic Ocean.
\end{abstract}

Keywords:

Case study $•$ GNSS $\cdot$ Sea surface height $•$ Ship-based $\bullet$ Ship dynamics

(c) Versita sp. z o.o.

Received 15-06-2012; accepted 12-08-2012

\section{Introduction}

During the last decade the observation of sea surface heights (SSH) became more and more important since the resulting data is of major interest for progress in different areas (e.g. oceanography, geodesy, geophysics) including environmental studies and other applications (e. g. early warning systems). Satellite altimetry is used as a standard method particularly in the open ocean to derive dense information on the mean sea level and its variation (Bosch and Savcenko 2010). Nowadays observations by means of (GNSS) Global Navigation Satellite System reflectometry give additional

*E-mail: reinking@jade-hs.de

VERSITA data of SSH and its change (Semmling et al. 2011) but these are still quite sparse. On the background of the basic ideas and goals of (GGOS) Global Geodetic Observing System (Plag et al. 2010) on the integration and combination of the space geodetic observations, independent in-situ measurements of $\mathrm{SSH}$, in addition to remote sensing methods, are desirable. In-situ measurements can in particular be used to validate results from remote sensing methods and therefore increase the reliability of observed changes in sea surface heights. GNSS-equipped buoys can be used to observe $\mathrm{SSH}$, but to cover a wider area a moving platform would be more suitable. Hence, ship-based GNSS observations seem to be an appropriate and efficient additional tool for the determination of SSH. Considering that the oceans are used for $90 \%$ of the worldwide transport of goods a very large area of the world's waters is traversed by moving merchant ships. According to a report by the 


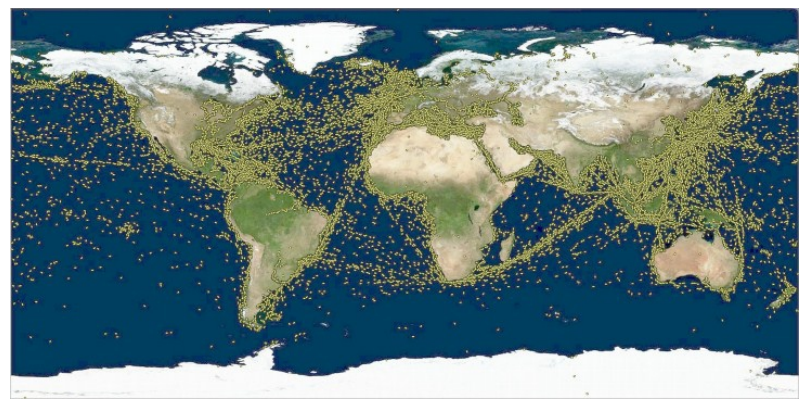

Figure 1. Vessel position reports received from NORAIS during 24 hours, $29^{\text {th }}$ June 2010 , source FII, ESA.

Norwegian Defence Research Establishment (FFI) on the ship tracking system (NORAIS ) aboard the (ISS) International Space Station (Eriksen et al. 2010) at least 60.000 ships are sailing the oceans at any time (Fig. 1). If only a small portion of these ships can be used for the determination of SSH a significant amount of valuable data can be derived with independent methods. The idea to use shipbased GNSS measurements is not new. Different groups used shipborne measurements in the past e.g. to calibrate satellite-based radar altimeters (e.g. Bonnefond et al. 2003; Shum et al. 2003; Schöne et al. 2002; Watson et al. 2003) or to map the local mean sea level (MSL) (Rocken et al. 2005; Foster et al. 2009, Bouin et al. 2009, Pineau-Guillou and Dorst 2011). Most of the ship-based data is derived in coastal areas were the distance to a land-based fixed GNSS reference station is short enough to allow for a high-quality estimation of GNSS-derived heights. For offshore areas, and open oceans in particular, the amount of available data is much smaller. The latest developments of GNSS precise point positioning (PPP) processing should allow to derive antenna heights with accuracies between 5 and $10 \mathrm{~cm}$ also in remote areas. Therefore, research vessels and some well-selected merchant ships could be used as moving platforms to record GNSS measurements. In addition, ship based in-situ measurements of SSH in the open ocean can be used to double-check results from satellite altimetry and GNSS reflectometry on a permanent basis. If a ship is used as a platform one has to know the exact distance between a GNSS antenna aboard and the undisturbed water surface. As long as the ship is not moving only the fixed antenna height and the hydrostatic correction due to draft changes have to be accounted for. When the ship is under way it produces a wave system around the hull which extends into a considerable area of influence (Fig. 2, derived from Computational Fluid Dynamics simulation (CFD)) leading to an apparent change of draft and trim of the ship. Therefore a GNSS antenna aboard a ship changes its height above the undisturbed water level significantly due to the hydrodynamic effect called squat. Some groups used ship-based radar systems to observe the distance of a GNSS antenna above the sea level but neglected that the wave system around the ship does not represent the undisturbed water surface that should be observed (Foster et al. 2009). Other groups

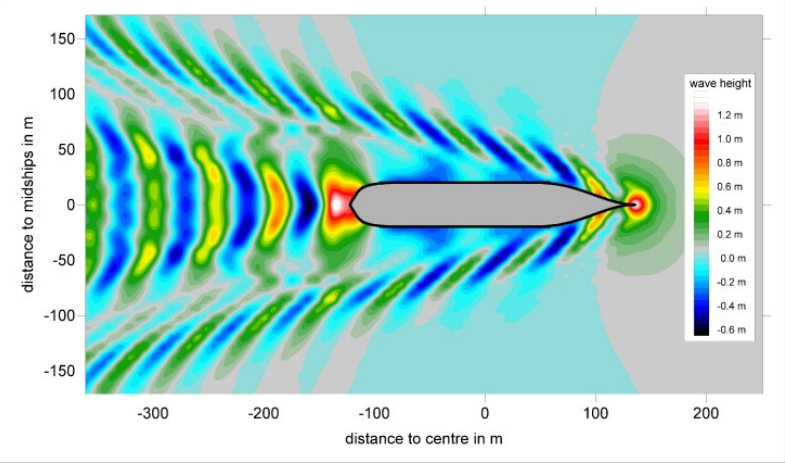

Figure 2. Wave system of a container ship, length $280 \mathrm{~m}$, width $40 \mathrm{~m}$, draft $11 \mathrm{~m}$ at a speed of $9 \mathrm{~m} / \mathrm{s}$. Data derived from CFD calculations by authors.

tried to find a simple approximation of the ship's squat but did not take into account the physical nature of this effect (Bouin et al. 2009, Pineau-Guillou and Dorst 2011). Obviously there is confusion in the geodetic community on the physics of some hydrodynamic effects and how they should be accounted for properly. Since an unsuitable treatment of hydrodynamic corrections can lead to systematic errors of some decimeters it seems advisable to draw the awareness of geodesists on this point. In this paper we will give an overview of the methods and the corrections that have to be applied for the estimation of SSH using ship based GNSS measurements. In Section 2 we discuss the physical effects that influence the height of a GNSS antenna onboard a ship over the unperturbed water surface. After a brief description of static, dynamic and external influences, their magnitude and possible corrections, we focus on the dynamic effect of the ship's motion. Section 3 describes the physical basics of the prominent hydrodynamic squat effect, its dependence on ship's speed and water depth and the estimation of correction values from numerical simulations and full-scale experiments. In Section 4 we present as a case study an experiment carried out on a cruise vessel on the Atlantic Ocean between Tenerife and Madeira Islands in March 2011. The data analysis and determination of hydrostatic and hydrodynamic corrections are described in detail and the quality of the results is estimated. Section 5 concludes our findings and gives an outlook to possible future developments.

\section{Ship dynamics}

A moving ship has 6 degrees of freedom. Translations and rotations can be observed by a field of GNSS antennas installed aboard the ship. The axes of small, quasi-static roll and pitch motions intersect in a point called the longitudinal centre of floatation (LCF), which is the centre of the waterline area. We shall use this point to reference the site of measurement. We can assume that the position of a GNSS antenna in the ship's body frame can be obtained from conventional surveying techniques with respect to the gen- 
eral arrangement plan to an accuracy of a few dm. Typically, the antenna position is displaced from the LCF by almost half the ship's length. Therefore, with moderate roll and pitch angles, the uncertainty in the antenna position alongship and athwartship will have negligible influence on the height determination. However, the vertical coordinate must be calibrated after the equipment has been installed. Statically, the draft is obviously changed by cargo operations. Additionally, all vessels carry deadweight in fuel bunkers and water ballast tanks. Given the exact mass distribution, the cargo computer produces the actual values of draft, trim and list. Often, however, the mass distribution is not known exactly and the values given by the cargo computer can be in error by several $\mathrm{dm}$, depending on the type of vessel. At the beginning or end of a voyage it is possible to check the values by reading the draft marks on the hull or by the use of static pressure sensors. During a voyage the draft characteristics change due to the consumption of fuel oil and the re-distribution or exchange of ballast water. On a typical container vessel, such as the one underlying Fig. 1, one day's fuel consumption would reduce the draft by about $1 \mathrm{~cm}$. From the engine log it should be possible to keep track of this influence rather well. The need to exchange ballast water at sea arises from the international ballast water convention, which aims to prevent the transport of invasive organisms into areas in which they would be harmful to biodiversity. Provided these operations are well documented, they will not give rise to significant errors. A problem, which should be addressed rather thoroughly, is the variability of water density, because its influence differs substantially according to the measurement scenario. A change of $1 \%$ in water density will result in a draft change of between $0.5 \%$ and $1 \%$, depending on the shape of the ship's hull. Water density is a function of salinity and temperature - compressibility can be neglected down to depths reached by ships' keels. Between a fresh water port and open sea the density increases by typically $2.3 \%$. Between various areas of the open ocean differences up to $0.6 \%$ are observed and accurate data is available in near real-time from the Aquarius satellite (Lagerloef et al. 2008). Consequently, if a voyage starts in a salt water port, draft changes due to variations in water density can be followed with negligible error. If a voyage starts in a fresh water port, the difference to open ocean is more pronounced, but can still be corrected rather accurately. For a ship setting sail from a brackish water port the correction of draft poses more of a challenge, because water density depends quite unpredictably on tide and fresh water contributions. Port authorities usually operate salinity and temperature sensors at tide gauge sites and these data would have to be taken into account meticulously during processing. External influences on the antenna ellipsoidal height include tide-related effects, currents, atmospheric pressure and geoid undulations. In the test experiment described in Chapter 4 these influences were considered best possible with the limited data available. In a future concept of continuous GNSS-based SSH measurement acquisition on a large number of vessels, the data would be fed into a global model where the external influences can be treated as adjustable

\section{VERSITA}

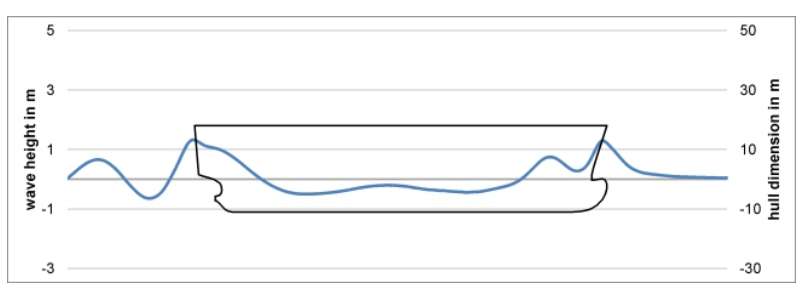

Figure 3. Typical wave system of a container ship in open sea, speed $9 \mathrm{~m} / \mathrm{s}$. Data derived from CFD calculations by authors, rescaled longitudinal cut.

unknowns. Dynamically the antenna height is affected by wave induced heave, roll and pitch. To correct for this influence single receiver epoch-to-epoch phase differences can be used to compute coordinate differences in time, integrate the vertical component and later on high-pass filter the results to avoid the accumulation of errors (Reinking and Härting 2002). The applied method is explained in detail in Section 4.4. From several years of experience we are confident that the quality of the correction thus obtained is in most cases excellent. However, a pronounced ocean swell of very long period would be problematic, demanding an impracticably low filter cutoff. A ship at sea is surrounded by its own wave system (see Fig. 2), which is hydrodynamically generated by the moving hull. It consists primarily of a bow and stern wave and a trough in the middle. To maintain hydrostatic equilibrium the centre settles in a lower position and there may be a change of trim. This phenomenon is called "squat". In shipping practice the main concern about squat is the reduction of under-keel-clearance, especially since squat is more pronounced in restricted waters than at open sea. For the ship-based observation of $\mathrm{SSH}$, of course, the change in absolute height is important. One of the key purposes of this paper is to show how the squat effect can be correctly included in the determination of sea surface height.

\section{Squat Corrections}

In first approximation the squat effect is governed by Bernoulli's equation, which, for an incompressible fluid, can be stated as

$$
v^{2}+2 \times g \times h=\text { const } .
$$

where $v$ is the velocity of flow in the ship's frame, $g$ is the gravitational acceleration and $h$ is the height. The equation states that the sum of dynamic and hydrostatic pressures is constant along a streamline. Compared to a moving point the ship's hull deflects the streamlines and forces particles to flow along elongated paths. Yet, the particles must reach their destination in the same time as if the ship were not present. As a result, the flow velocity is increased alongside the hull and the corresponding change of hydrostatic pressure creates the typical wave system depicted in Fig. 3. Whereas the principle can be understood with Bernoulli's equation, a computation of the amount of squat requires the knowl- 
edge of the velocity field in a volume around the ship's hull. Numerical calculations are usually done by solving a three-dimensional partial differential (Laplace-) equation. As this approach neglects friction, the results are only approximate and experimental validation is advisable. It is important to note that the unperturbed water level, to which squat must be referred, is nowhere present in the immediate vicinity of the vessel. It is not possible to measure squat directly with onboard sensors. An instrument detecting the water surface would have to look at an extreme glancing angle and a pressure gauge on the hull would only detect the hydrostatic pressure, which more or less corresponds to the deformed water surface. Today, all reliable methods of measuring squat are based on GNSS equipment onboard the investigated vessel. Where landbased reference stations are available, the height variations of the onboard antennas can in general be easily determined. The unperturbed water level must be inferred from tide gauge readings, which, depending on the ship's distance to the tide gauge sites and wind influence, can be a rather error prone process. As an alternative the authors developed the SHIPS-method (Härting and Reinking 2002), in which the unperturbed water level is represented by an escort craft equipped with a single GNSS-receiver. The escort craft travels ahead of the investigated vessel, far enough to be outside its wave system, but close enough to justify the assumption of identical tide levels and geoid heights. By eliminating the need for fixed reference stations, tide gauges and a perfect knowledge of the geoid, the SHIPS-method features more versatility and accuracy, provided the dynamic behaviour of the escort craft is known. For any particular vessel squat is a function of speed and cross section of the waterway. The latter is only important if width and depth are within certain limits. For the depth of influence Barrass (2004) quotes

$$
\frac{4.44}{C_{b}^{1.3}} \cdot T
$$

where $T$ is the static draft and $C_{b}$ is the block coefficient. $C_{b}$ is the quotient of the vessel's displacement and the surrounding cuboid calculated from ship's length between perpendiculars, its width and the mean static draft and describes the shape of the hull. A similar empirical expression holds for the width of influence. From these we can typically state that, in a waterway deeper than 6 times its draft and 10 times its breadth a vessel's squat will be the same as in the open ocean. In the SHIPS-method the escort craft's draft should be small compared to the investigated vessel, such that its squat can be treated as depending on speed only. Then, a onedimensional calibration function is sufficient to correct for squat. This calibration function is obtained from a separate experiment, in which the escort craft is operated in the vicinity of a floating platform equipped with GNSS. The boat is run at various speeds with stopping in between and the height differences are analyzed. An analogous calibration can be carried out for a large vessel, preferably with an escort craft that has been calibrated independently. The depth of influence is, of course, larger, but for experiments in the open sea a squat correction depending on speed only will be sufficient. For relatively wide and shallow areas, such as the southern part of the North Sea, a correction depending on speed and depth may be necessary. To produce such a two-dimensional calibration is more elaborate, but possible (Härting et al. 2004). Calibration of both, escort craft and large ship would severely be complicated by the presence of a long oceanic swell. Such sea conditions should be avoided during calibration. In SSH determination with a calibrated ship averaging over a minute or so should be justified, which would eliminate all but the longest waves.

\section{Case study}

\subsection{Experimental Setting}

To validate the possibilities and the limits of ship-based SSH observation we carried out an experiment on a vessel that sailed from St. Cruz de Tenerife to Funchal, Madeira (Fig. 4a) on March 19th and 20th 2011. The ship used in this case study was the AIDAblu, a cruise vessel with an over-all-length of $252 \mathrm{~m}$ and a width of $32 \mathrm{~m}$ (Fig. 4b). For the determination of here squat behaviour during her approach to Funchal we decided to apply the SHIPS method to avoid error-prone tide gauge extrapolations of Funchal tide gauge data. Hence an escort craft was used accordingly. For this purpose a fast boat was chartered, the Oceanod roma (Fig.4c), that is commonly used for touristic and scientific whale watching tours. It has a maximum speed of $40 \mathrm{kts}$ and is capable to sail up to a distance of 10 to $15 \mathrm{~nm}$ off the shore of Madeira. Unfortunately the Oceanodroma is an open boat so it was only possible to use rugged equipment. Hence, we decided to use a GPS receiver only and avoided the installation of additional inertial measurement units. Three dual-frequency Trimble 4700 GPS receivers and Compact L1/L2 antennas without ground plane were installed aboard the cruise vessel, one at the foremast and two at starboard and port side close to the stern leading to a distance between the aft receivers and the one installed at the foremast of $188 \mathrm{~m}$ and between the starboard and port side receivers of $32 \mathrm{~m}$. Another receiver and antenna of the same type was used aboard the escort craft. The experiment started on the evening of March 19th at 19.00 UTC, approx. $2 \mathrm{~h}$ before the AIDAbluleft the harbor of St. Cruz, and ended on the following day at 15.00 UTC, approximately $2 \mathrm{~h}$ after berthing in Funchal. The escort craft left Madeira in the morning of March 20th to meet up with the AIDAblu at approximately 10.30 UTC in a distance of about $10 \mathrm{~nm}$ off the coast of Madeira and convoyed the cruise vessel up to her mooring in Funchal. All receivers collected GPS raw data with a sampling rate of $1 \mathrm{~Hz}$. Sea and wind conditions were calm to moderate with wave heights of about $1 \mathrm{~m}$. Apart from the GPS data additional information was recorded before, during and after the cruise to ensure a proper consideration of all influencing effects. As described before, the squat of a vessel is a combination of the dynamic change of draft and trim. The centre of rotation of the ship's hull is free of a trim-dependent height change and therefore an appropriate 


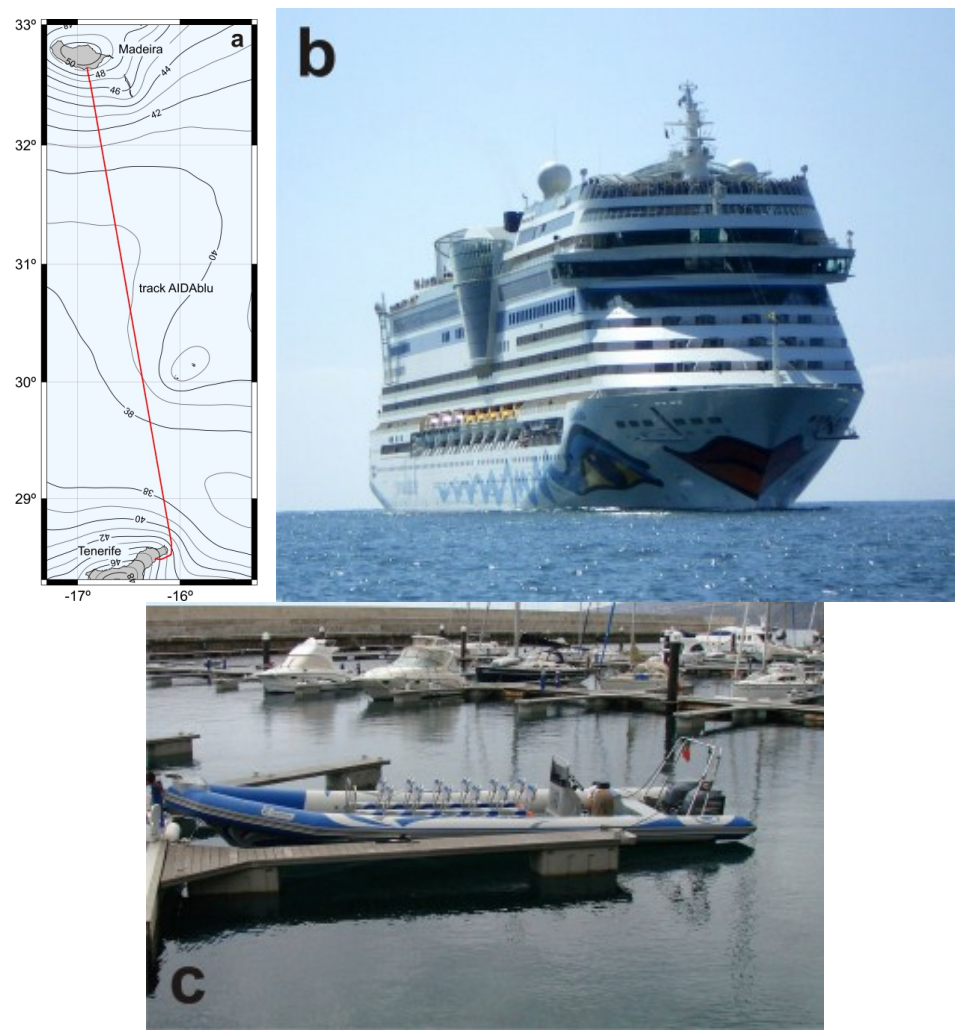

Figure 4. Measured track between Tenerife and Madeira in the Atlantic Ocean, contour lines of EIGEN-6C geoid (a), cruise vessel AIDAblu used in this study (b), escort craft Oceanodroma used for calibration of cruise vessel's squat (c).

reference point to describe the relevant apparent sinkage of the ship's hull. Even though, strictly speaking, the centre of rotation is changing dynamically, the longitudinal centre of floatation (LCF, see section 2 above) can be used as a good approximation. The coordinates of the LCF in the ship's reference frame (SRF) were taken from the loading computer of the vessel and additional manual draft readings in both ports were used to verify particularly the vertical component of the LCF position. To derive the LCF position in a global reference frame later on, the GPS antenna positions in SRF were taken from the general arrangement plan of the vessel and calibrated by GPS-derived static coordinate differences and draft readings at the berth in Funchal. Data from the vessel's voyage data recorder (VDR) for the whole cruise in conjunction with data from the loading computer were used to estimate draft changes due to fuel consumption or variation of water density. This is done by dividing the information on displacement changes by Tonnes per centimeter (TPC) values, (mass required to increase or decrease a ship's mean draft by $1 \mathrm{~cm}$ ). The values of water density show no variation, hence not correction was applied. To ensure a proper estimation of the relevant speed through water manual recordings of the velocity measurements from the ship's Doppler log in deep water were taken and later compared with revolution-per-minute data (RPM) of the propellers from VDR and speed over ground de- rived from GPS data. Additional tide gauge data and GNSS data from fixed reference stations were taken for data validation and quality check:

- 30-sec GNSS data from TN01 reference station in Sta. Cruz de Tenerife, provided by Instituto Geográfico Nacional of Spain

- 5-min tide gauge data from the port of St. Cruz de Tenerife, provided by Instituto de Astronomía y Geodesia, Universidad Complutense Madrid, Spain

- 5-sec GNSS data from FUNC reference station in Funchal, Madeira, provided by Instituto Geográfico Português, Portugal

- 1-min tide gauge data from the port of Funchal, Madeira, provided by Instituto Hidrográfico, Portugal

Supplementary global geoid and ocean tide model data were used:

- Geoid heights calculated by the International Centre for Global Earth Models (ICGEM) (Barthelmes 2009) using EIGEN-6C model (Fórste et al. 2011)

- Global ocean tide model parameters of DTU10 (Cheng and Andersen 2010) 


\subsection{GPS data processing}

The GPS data processing was carried out by different analysis strategies using three software packages: Self-developed software was used to derive changes of the global Cartesian coordinates between every pair of consecutive measurement epochs of the antenna reference points (ARP) by an epoch-to-epoch carrier phase double difference approach (Reinking and Hárting 2002, Reinking 2010) with a quality of better than $1-2 \mathrm{~cm}$. From the resulting data the course and speed over ground as well as the heave of the ships can be derived. A likewise self-developed dual-frequency carrier phase double difference software package with MLAMBDA ambiguity resolution (Chang et al 2005) was used in a movingbaseline mode to calculate kinematic coordinate differences either between the ARPs of the receivers aboard the ship themselves or between any one of them and the escort craft. The same software was used in a standard kinematic mode for coordinate differences between any of the moving receivers and a fixed reference station. Our software was developed, tested and used during the last decade in more than 100 full-size squat experiments and generates centimeter level relative coordinate differences (Hárting et al. 2004, Reinking and Hárting 2007). The coordinates of the ARPs in IGS08 reference frame were derived from PPP processing using Bernese software 5.0 (BSW) (Hugentobler et al. 2006, Teferle et al. 2007, Geng et al. 2010). We used 5-sec satellite clocks, earth orientation parameters and orbits from CODE (Center for Orbit Determination in Europe) (Dach et al. 2009) to avoid inconsistencies. Due to a lack of memory of the receivers aboard the cruise vessel we had to download the data en-route and restart data collection. Therefore the data sets of the receivers contain gaps of some seconds leading to a set-up of new carrier phase ambiguities for all satellites at the beginning of a new time segment. The time segments with continuous data have a length of not less than 5 hours so that a sufficient quality of the resulting coordinates from a PPP solution can be expected. However, all segments for a single receiver were introduced into a common processing to assure a proper estimation of tropospheric parameters and to avoid related coordinate jumps between the time segments. The results of all three processing modes were used to derive the ship's attitude and the relative position of the LCF, the heave of the escort craft and the cruise vessel and the final coordinates of the LCF in IGS08 reference frame.

\subsection{Ships attitude and relative coordinates of LCF}

The data from the receivers aboard the cruise vessel were processed using precise CODE satellite ephemeris in a moving baseline mode relative to the receiver at the foremast and yield $3 D$ Cartesian coordinate differences between the ARPs with respect to IGS08. The resulting coordinate differences were transformed to local plane coordinate differences. Ships attitude and the coordinate differences in IGS08 of the LCF relative to the receiver at the foremast can be derived from a simple 3D transformation of the antenna and LCF coordinates in SRF. As mentioned before, the

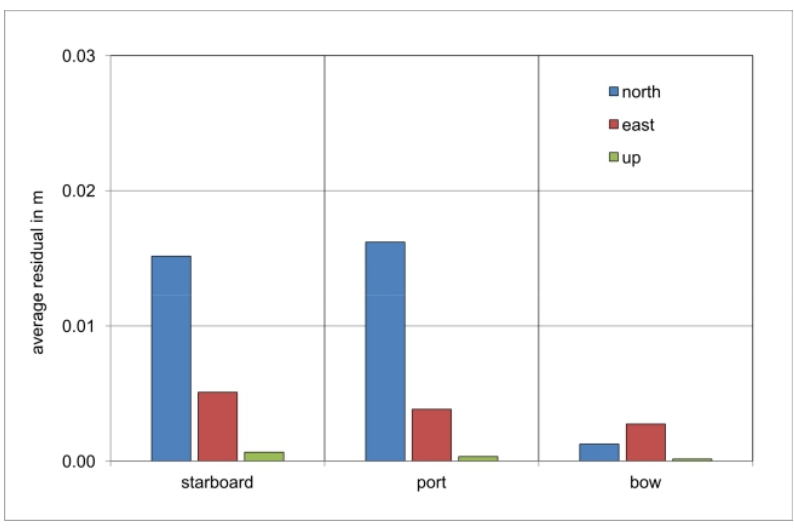

Figure 5. Average absolute residuals of transformation of ship frame coordinates of GNSS antennas to GNSS- derived 3D coordinate differences in IGS08.

antenna coordinates in SRF were derived from readings of the general arrangement plan which gives in this case a quality not better than $0.5 \mathrm{~m}$. To ensure high-quality coordinates, particularly in the height components, we processed the GPS data from the receivers aboard the cruise vessel relative to the one on the escort craft in the port of Funchal without motion of both platforms and derived the coordinate differences of the ARPs. The height of the ARP on the escort craft above the water level was measured by tape. Since the LCF at berth represents the water level and its height in SRF is wellknown from draft readings, the heights of the ARPs of the receivers aboard the cruise vessel relative to SRF could be adjusted to derive the correct height difference to the water level later on. The horizontal components were fitted according to horizontal distances derived from GPS processing. The position of both aft receivers athwartship was kept fixed because the antennas were installed on a construction of the superstructure of the vessel for which the hull frame position is well-known. Both aft receivers were installed symmetrically with respect to the amidships axis. The average absolute residuals of the 3D transformation are shown in Fig. 5. The ship sailed to north during most of the time. Hence, the larger average residuals for northern direction are a result of a less perfect fit of the longitudinal antenna positions of the port and starboard antennas in SRF. A discrepancy in the longitudinal distances of these antennas to the bow antenna leads to larger residuals for the aft antennas but not for the one at the bow. The vertical component fits very well because the longitudinal extension of the network is six times the lateral extension and therefore vertical discrepancies are easily absorbed by small variations of the rotation angles. Low-pass-filtering of the resulting pitch leads to the dynamic trim which can be reduced by the static trim to derive the dynamic trim change (Fig. 6). For bulk carriers this trim change is commonly strongly correlated with the speed of the vessel while for container ships it depends additionally on the static draft of the ship. It has been shown that, for container ships, the dynamic trim changes only slightly if the bulbous bow is just submerged 


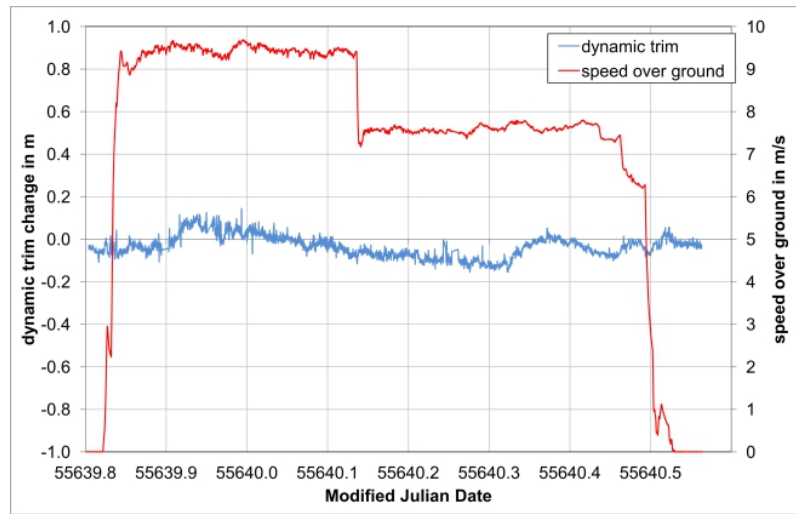

Figure 6. Dynamic trim change and speed over ground of the cruise vessel during the experiment.

completely (Reinking et al. 2009). This was also the case during this experiment with the AIDAblu which has a hull shape close to the form of a container ship. Therefore the dynamic trim change does not show a velocity-related systematic behaviour. The trim changes linearly between Modified Julian Dates (MJD) 55639.92 and 55640.32 which could be a result of the fuel consumption. Though small, changes in displacement may lead to a trim change as the bunkers are separated from the centre of buoyancy.

\subsection{Heave of escort craft, heave and speed of the cruise vessel}

\subsubsection{Heave determination}

Double-differences of carrier phase between consecutive epochs can easily be used to derive 3D coordinate differences between epochs. If these differences are cumulated, the result will be influenced by possibly short and long term neglected systematic effects (e.g. tropospheric effects or satellite and receiver clock drift) but also by a random walk. Although very good approaches are used in GNSS processing to reduce the influence of systematic effects, the random walk as a long-term variation can only be eliminated by appropriate filtering of the cumulated coordinate differences. Applying an adequate filtering will additionally reduce long-term systematic effects not modelled properly. If the vertical component of the cumulated coordinate differences for a GNSS antenna aboard a ship is high-pass filtered the wave-induced vertical motion or heave of the antenna can be determined exactly for the observation epochs and positions. In this investigation we used a 6th order Butterworth digital high-pass filter (Parks and Burrus 1987) with $0.025 \mathrm{~Hz}$ cut-off in a forward-backward application. The selected cut-off reduces effects with a period longer than about $40 \mathrm{~s}$ and seems to be adequate since we assume that waves show only shorter periods in moderate sea conditions (Van Dorn 1993).

VERSITA

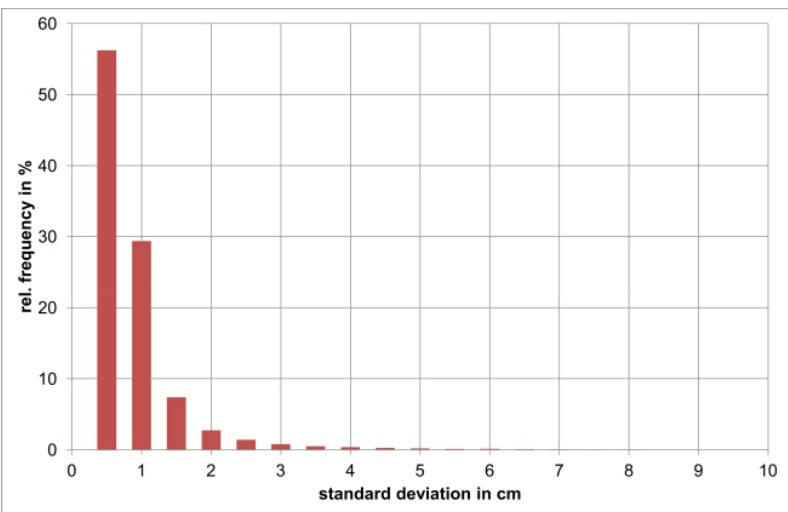

Figure 7. Histogram of standard deviations of heave determination for the cruise vessel for all epochs.

\subsubsection{Heave determination of GNSS antenna aboard the escort craft}

The escort craft was equipped with a single receiver installed at the stern of the boat at a height of about $1.9 \mathrm{~m}$ above sea level and $0.37 \mathrm{~m}$ to port from amidships. Therefore, a short-periodic but stochastic pitch will lead to a likewise short-periodic, stochastic height variation that cancels out if averaged. This need not necessarily hold for a short-periodic but stochastic roll of the boat. Due to the low antenna height above the rotation axis, which can be assumed to be at water level, up to a roll angle of $5^{\circ}$ the influence is less than $2 \mathrm{~cm}$ and hence in the order of the achievable height quality. With respect to the shape of the escort craft's hull it can be assumed that, particular at higher speeds, the roll amplitude will not exceed this limit. In fact, at higher speeds a long-periodic heel change-corresponding to the direction of the incoming waves and wind - might occur, which cannot be corrected by this approach and has to be accounted for in a different way.

\subsubsection{Heave determination of $L C F$ of the cruise vessel}

Before the height differences are used to derive the heave of the cruise vessel the vertical influence from pitch and roll must be eliminated. For this purpose, the changes of the pitch and roll angles between the epochs are derived from the above mentioned attitude determination and used to correct the coordinate differences of the successive epochs. Afterwards, the differences were cumulated and filtered to derive the heave for every single antenna. The results must be equal since they should describe the vertical movement of the whole ship. Therefore the single heave values are averaged for every distinct epoch to derive the heave of the ship's LCF. The average standard deviation for the heave is $0.007 \mathrm{~m}$, the histogram of the standard deviations for all epochs is shown in Fig. 7. At this place a remark on accuracy limitations in heavy seas is in order. Dynamically the roll and pitch axes vary in height and the static LCF - even if heave-corrected and averaged - can develop an offset from the water line. For a ship like AIDAblu we expect that this becomes significant from roll angles of $10^{\circ}$ to $15^{\circ}$. Investiga- 


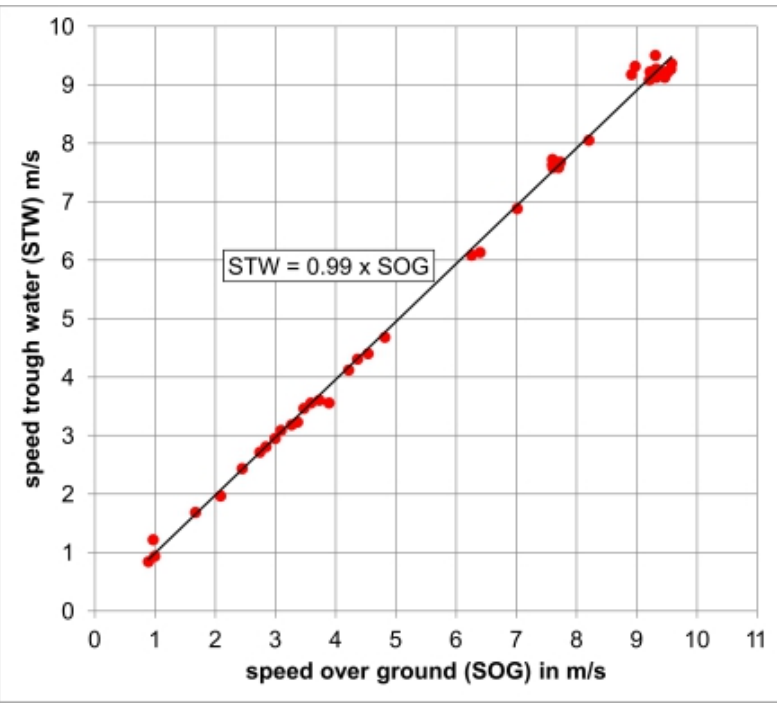

Figure 8. GNSS-derived speed over ground (SOG) and manually recorded speed through water (STW) of the cruise vessel.

tions on ship motion in waves, which could lead to a model for correcting such an error, are a subject of present studies. Speed determination The cumulated horizontal components of the coordinate differences are low-pass filtered to derive the speed over ground (SOG) of the AIDAblu with a high quality, but hydrodynamic effects are correlated with the speed trough water (STW). The STW from the Doppler log was not recorded in the VDR data, so we recorded it manually for the major part of the journey while the vessel sailed in deep water. The relation between STW and SOG is plotted in Fig. 8 and can be stated as linear with a constant factor of 0.99 . Therefore, we assume no hydrodynamically relevant current in this area during the experiment and will use the SOG as STW. If current is assumed to be negligible the SOG of a vessel is related to RPM of the ship's propeller and headwind. Figure 9 shows the raw data of headwind and RPM taken from VDR and SOG from GPS. Only the segments with constant RPM (no acceleration) were used to derive a simple relation of SOG as a linear function of RPM and a quadratic function of headwind. The residuals can be interpreted as a combination of slip of the propeller and a neglected current. The maximum value of the residuals rarely exceeds $0.3 \mathrm{~m} / \mathrm{s}$ and the average absolute value is $0.07 \mathrm{~m} / \mathrm{s}$ which can be neglected from a hydrodynamic perspective.

\subsection{PPP solution and LCF coordinates}

The GPS data sets were independently processed using BSW. We reduced the sample rate of the GPS data to $5 \mathrm{~s}$ to avoid any effect of possible interpolation of satellite clocks and also to reduce processing time. The maximum speed of the vessel is about $9.5 \mathrm{~m} / \mathrm{s}$ so that the distance between data points will be still less than $50 \mathrm{~m}$. No data for ocean tide loading were introduced but earth tides were

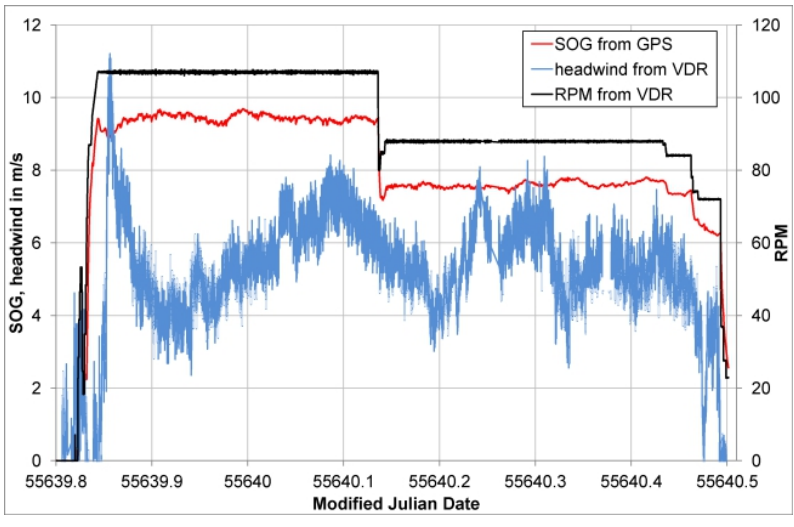

Figure 9. GNSS-derived speed over ground (SOG), headwind and RPM data from ship's VDR during the experiment.

accounted for to enable a later calculation of the result in a conventional tide free reference frame whereupon ocean tide loading must be applied too. The resulting 3D Cartesian coordinates are related to IGS08 reference frame. To derive the 3D Cartesian coordinates of the LCF in IGS08, the 3D coordinate differences of the antenna's ARPs and LCF from the moving baseline solution were transformed to the PPP solution. Only a translational transformation was applied because the attitude is described by the coordinate differences with a higher quality than using PPP results. The residuals of this transformation can be used as good quality criterion for the PPP results and to detect and eliminate gross errors. Figure 10 presents a histogram of the standard deviation of the translational transformation of all epochs. The average standard deviation is $3.4 \mathrm{~cm}$ for the north, $2.5 \mathrm{~cm}$ for the east and $6.1 \mathrm{~cm}$ for the up component, but the maximum value for the upward component exceeds $50 \mathrm{~cm}$. Therefore we eliminated all epochs showing a standard deviation larger than a threshold of $7.5 \mathrm{~cm}$ for north and east directions and $10 \mathrm{~cm}$ for the upward component, which corresponds to about two times the average standard deviations. About $21 \%$ of epochs exceeded all three thresholds. The average standard deviation of the remaining epochs is $2.1 \mathrm{~cm}$ for the north, $1.8 \mathrm{~cm}$ for the east and $3.7 \mathrm{~cm}$ for the up component. The GPS data of the beginning and ending of the journey was also processed up to a distance of about $25 \mathrm{~km}$ from the shore line of the islands with respect to the fixed reference stations in St. Cruz de Tenerife and Funchal in relative kinematic double-difference mode using self-developed software. The coordinates of the reference station in Funchal was taken from the weekly IGS solution (International GNSS service), the coordinates of the station in Tenerife were calculated relative to the Funchal station from a processing of GNSS data sets of GPS day 078 and 079 using BSW. Thus, for these sections, the LCF coordinates are derived independently and can be used to compare with the results from PPP processing. Because the PPP processing was carried out without introducing corrections for ocean tide loading, related effects are still

VERSITA 


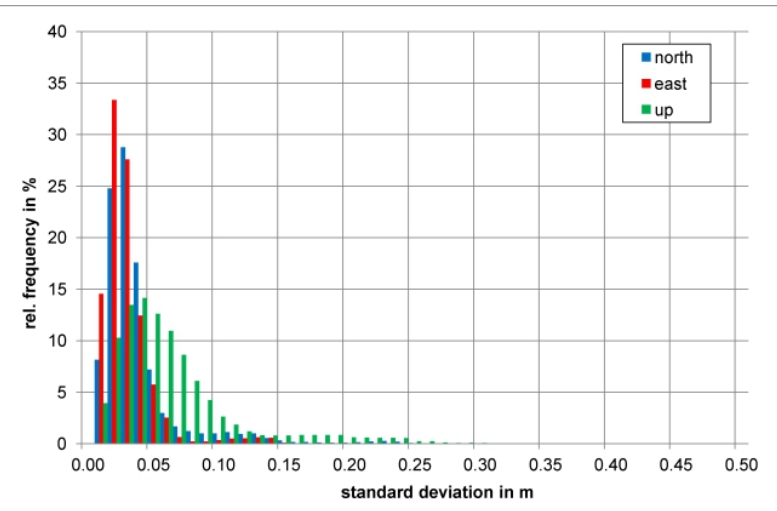

Figure 10. Histogram of standard deviation of north, east and up component from translational transformation of relative coordinates of GNSS antennas to the PPP-derived absolute coordinates.

present in the LCF coordinates. The LCF coordinates from relative kinematic processing were derived by adding the resulting coordinate differences between the antenna's ARP to the fixed coordinates of the reference station. Hence, these data are free of solid earth tide and ocean tide loading effects. For a comparison to BSW PPP results ocean tide loading has to be added to the LCF coordinates from the relative kinematic solution. Vertical displacements were calculated according to Petit and Luzum (2010) using the IERS Conventions (2010) software program hardisp.f (developed by D. Agnew, University of California, San Diego) based on ocean loading parameters derived from Bos and Scherneck free ocean loading provider (http://www.oso.chalmers.se/ loading/). To ensure a proper estimation of displacements we processed the GNSS data of both stations using BSW PPP mode without introduction of ocean tide loading parameters. The variations of the heights are compared to the displacements calculated with hardisp.f for Funchal and Tenerife, respectively. Figure 11 shows a good agreement between ocean tide loading displacements and height variations of both stations. The resulting differences for north, east and up components are shown in Fig. 12. For the departure (Fig. 12a) and arrival (Fig. 12b) the average differences are $1.2 \mathrm{~cm}$ resp. $1.4 \mathrm{~cm}$ for the east, $0.0 \mathrm{~cm}$ resp. $-0.5 \mathrm{~cm}$ for the north and $3.3 \mathrm{~cm}$ resp. $3.6 \mathrm{~cm}$ for the up component. Considering that the results for the LCF coordinates from the relative kinematic solution have a quality of 1 $2 \mathrm{~cm}$ for the horizontal and $2-3 \mathrm{~cm}$ for the vertical components, it seems permissible to assume a quality of the BSW PPP result for the LCF coordinates of $2-3 \mathrm{~cm}$ for the horizontal and $4-6 \mathrm{~cm}$ for the upward component.

\subsection{Calibration of escort craft}

Although small, the escort craft itself is influenced by hydrodynamic forces. Hence, the antenna height aboard the escort craft is changing depending on speed and this must be corrected if the

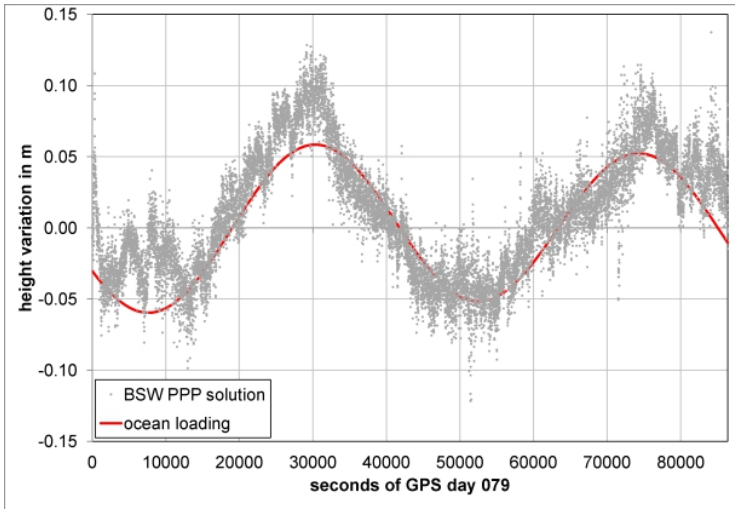

a

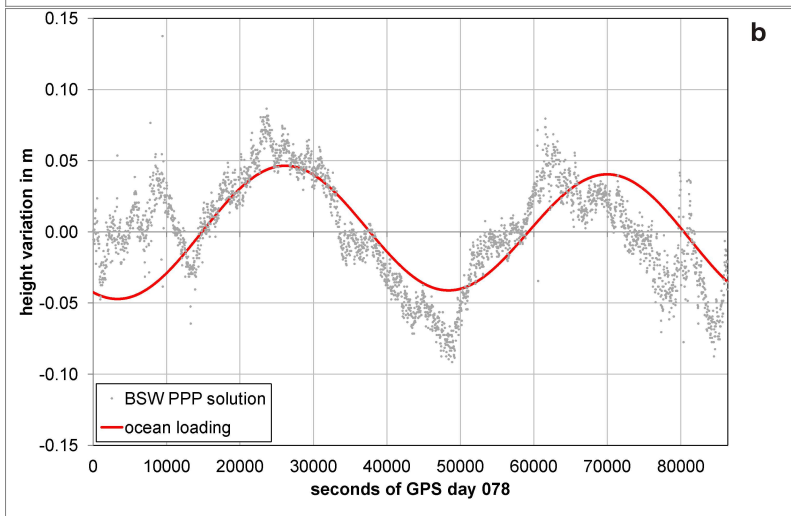

Figure 11. Height variation of kinematic PPP solutions and vertical displacement from ocean tide loading for reference stations in Funchal (a) and Sta. Cruz de Tenerife (b).

escort craft should represent the undisturbed water surface at the position of the cruise vessel while approaching Funchal. To derive a function that describes the hydrodynamic behaviour of the escort craft we carried out a calibration experiment at the port of Funchal in an "inverted" mode of the SHIPS method: the cruise vessel was used after berthing as a floating platform as a representation of the water level and the coordinate differences between the LCF of the cruise vessel and the ARP of the escort craft was calculated from the GPS relative kinematic processing using self-developed software. The escort craft was operated at various speeds in the vicinity of the cruise vessel (distance ranges from 600 to $1200 \mathrm{~m}$ ) and engine stop maneuvers were carried out several times. Since, on a small boat, this maneuver takes only a few seconds, the squat effect can be seen directly from the change in height differences between the LCF and the ARP at the escort craft after the heave for both ships has been applied. Figure 13 shows the height differences corrected for heave and the related speed of the escort craft. The height differences were reduced by the height of the ARP aboard the escort craft above water level. The data has to be cleaned for segments with acceleration and turns to avoid influences from related trim and heel effects. The remaining 644 data points are shown in Fig. 14. A thin-plate spline least squares ap-

VERSITA 


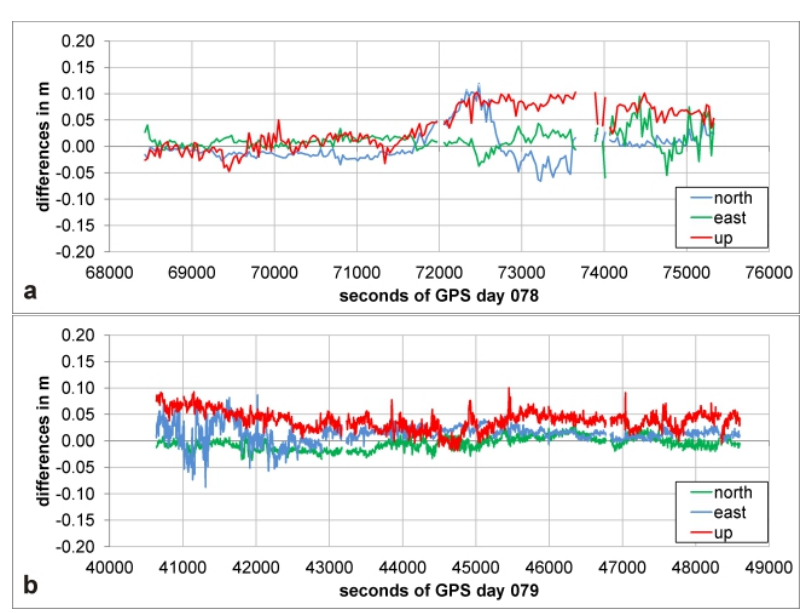

Figure 12. Differences of LCF coordinates from PPP solution and relative kinematic processing for departure (a) and arrival (b).

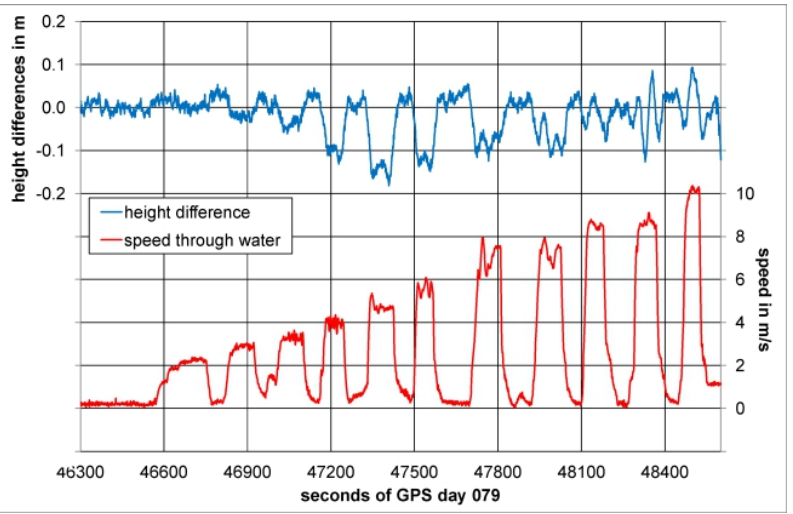

Figure 13. Heave corrected height difference between LCF and escort craft's ARP and speed through water of the escort craft in the port of Funchal.

proach (Franke et al. 1994) was used to derive a functional fit of the data yielding a standard deviation of $1.3 \mathrm{~cm}$. The resulting function describes a typical hydrodynamic behaviour of a small but fast boat (Hárting et al. 2007). The squat can be positive or negative according to whether the boat is in displacement or planing mode. For the escort craft used here the maximum displacement squat occurs at about $5 \mathrm{~m} / \mathrm{s}$. From $8.5 \mathrm{~m} / \mathrm{s}$ onward the dynamic lift dominates and the height increases considerably above the static value.

\subsection{Calibration of cruise vessel}

The height of LCF from relative kinematic processing of the departure from Tenerife and arrival in Madeira together with the height of the ARP of the escort craft, likewise derived from relative kinematic processing, were used to estimate the squat of the cruise ves-

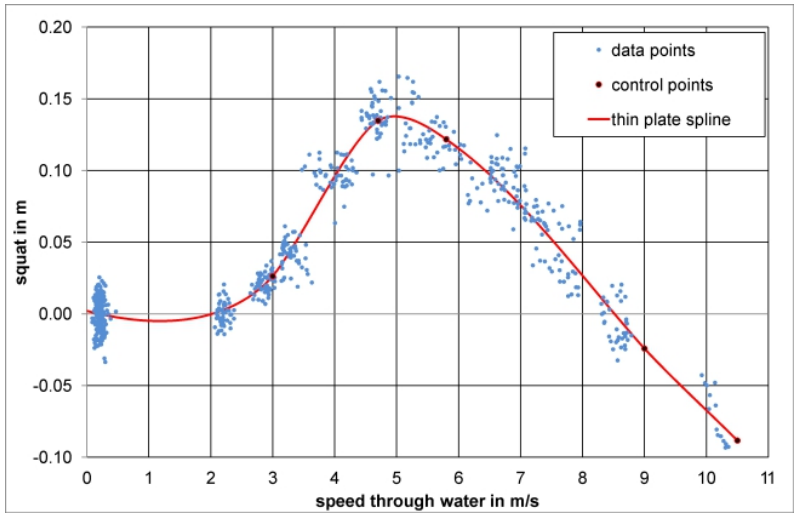

Figure 14. Speed-depending height variation of the ARP aboard the escort craft. Used data points and control points of least squares thin-plate spline adjustment and resulting thinplate spline function.

sel. The distance between the escort craft and the cruise vessel ranges between 1,5 and 0,2 $\mathrm{nm}$ during the approach of Madeira. The data of the departure was restricted to a segment of distance between $5 \mathrm{~km}$ and $25 \mathrm{~km}$ from the port of St. Cruz de Tenerife to eliminate data containing maneuverings at the beginning of the journey. The arrival data were reduced by a segment when the cruise vessel was travelling astern during the approach of her berth in the port of Funchal. Figure 15 shows the used tracks and contour lines of EIGEN- $6 \mathrm{C}$ geoid heights. The heave-corrected heights of the LCF and the ARP aboard the escort craft were reduced by the static values at the berth. Furthermore, we applied corrections for tidal variations derived from tidal heights at the ship's positions calculated using DTU10 model parameters which were checked against the tide gauge data from Funchal and St. Cruz de Tenerife. Additionally we applied geoid height variations from EIGEN-6C data and corrected the heights of ARP aboard the escort craft by the squat of the boat. The resulting heights with respect to the static position are shown in Fig. 16. Besides the squat of the cruise vessel the heights of LCF and the escort craft for Madeira contain the same systematic errors related to possibly inexact geoid height or tidal variations and dynamic sea level changes. The LCF heights at Tenerife are likewise influenced by possibly inaccurate geoid and tidal heights. These effects must be considered if the squat of the cruise vessel is to be estimated. Unfortunately, the escort craft was affected sideways by waves and wind from starboard leading to a long-periodic heel to the portside, which gradually reduced during the approach of Funchal as conditions calmed in the shadow zone of the island of Madeira. For an estimation of this influence a projective rectification was applied to two photos taken with a digital camera aboard the escort craft during the squat experiment in combination with one image from the port of Funchal in calm conditions (Fig. 17). The inclination of the horizon was measured to $11.6^{\circ}$ and $4.0^{\circ}$ giving a height offset of the antenna of $11.8 \mathrm{~cm}$ and $3.2 \mathrm{~cm}$ respectively. One of the photos was taken just after the pi- 

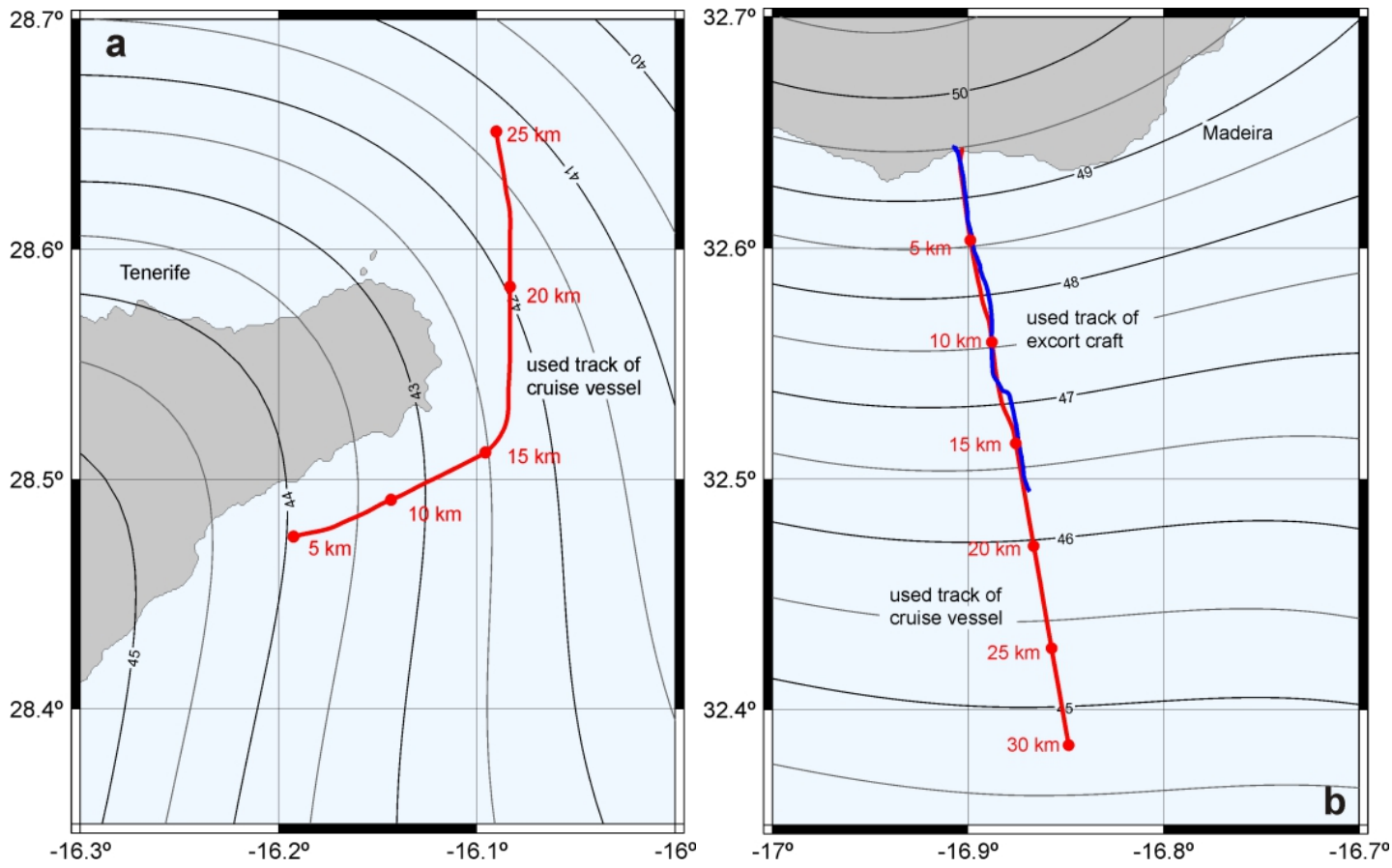

Figure 15. Tracks of cruise vessel and escort craft during departure (a) and arrival (b) used to derive a squat function for the cruise vessel. Sailed distance along the track (a) and distance from shore line (b) in km.

lot boarded the cruise vessel, so the time of the photo can be identified with an error less than $30 \mathrm{~s}$. The time marks of the photos taken from the stored image data were used to derive the recording time of the second photo. All observed data were introduced into a common least squares adjustment in which the systematic effects were estimated by the following functions:

- Squat of the cruise vessel as a pure quadratic function of the vessel's speed

- Systematic effects from inaccurate geoid and tidal heights at Madeira as a cubic function of the distance to Madeira coast line

- Systematic effects from inaccurate geoid and tidal heights at Tenerife as a 2D quadratic function of the latitude and longitude of the LCF

- Systematic heel of the escort craft as a quadratic function of the time

Different approaches for Madeira and Tenerife for the estimation of the systematic effects from inaccurate geoid and tidal heights were used because of the geometric structure of the cruise vessel's track. In the vicinity of Tenerife the track crosses the contour lines of the geoid height at different angles and covers an extended area (Fig 15a). During the approach of Madeira the track crosses the contour lines more or less rectangular. Hence, close to Tenerife a 2D functional approach is suitable while close to Madeira a 1D functional approach is preferred. The residuals of this adjustment with a standard deviation of $1.6 \mathrm{~cm}$ are shown in Fig. 18. Figure 19 presents the corrected LCF heights for Madeira and Tenerife and the resulting squat function. A confidence interval was created by doubling the standard deviation of $0.8 \mathrm{~cm}$ at the maximum speed of $9.5 \mathrm{~m} / \mathrm{s}$ and applied for all speeds. The squat of the AIDAblu reaches a value of $29.6 \mathrm{~cm}$ for the maximum speed of $9.5 \mathrm{~m} / \mathrm{s}$. If a maximum error in the speed through water of $0.3 \mathrm{~m} / \mathrm{s}$ is assumed according to the results from Chapter 4.1, the error in the squat value will still be less than $2 \mathrm{~cm}$ and therefore in the range of the measurement quality. To double-check the resulting squat, additional CFD calculations can be used. The exact hull form of the cruise ship was not available for this investigation, but calculations for different ship types with known hull forms and block coefficient $C_{b}$ (see Chapter 3 ) from former projects were used for comparison. The AIDAblu has a $C_{b}$ of 0.70 . CFD calculations were performed at different speeds for a tanker with $C_{b}=0.82$, a container ship at two drafts with $C_{b}=0.64$ and $C_{b}=0.69$ and a parabolic Wigley ship (Wigley 1926) with $C_{b}=0.44$. For every ship with different block coefficients a quadratic function was derived. The results are displayed in Fig. 20 together with the squat function of the cruise vessel from this investigation. The squat of the cruise vessels fits very well to the data from CFD calculations. This is emphasized by a plot of the speed factors of these functions in Fig. 21. The factors from CFD results are fitted with a quadratic function of the block coef- 

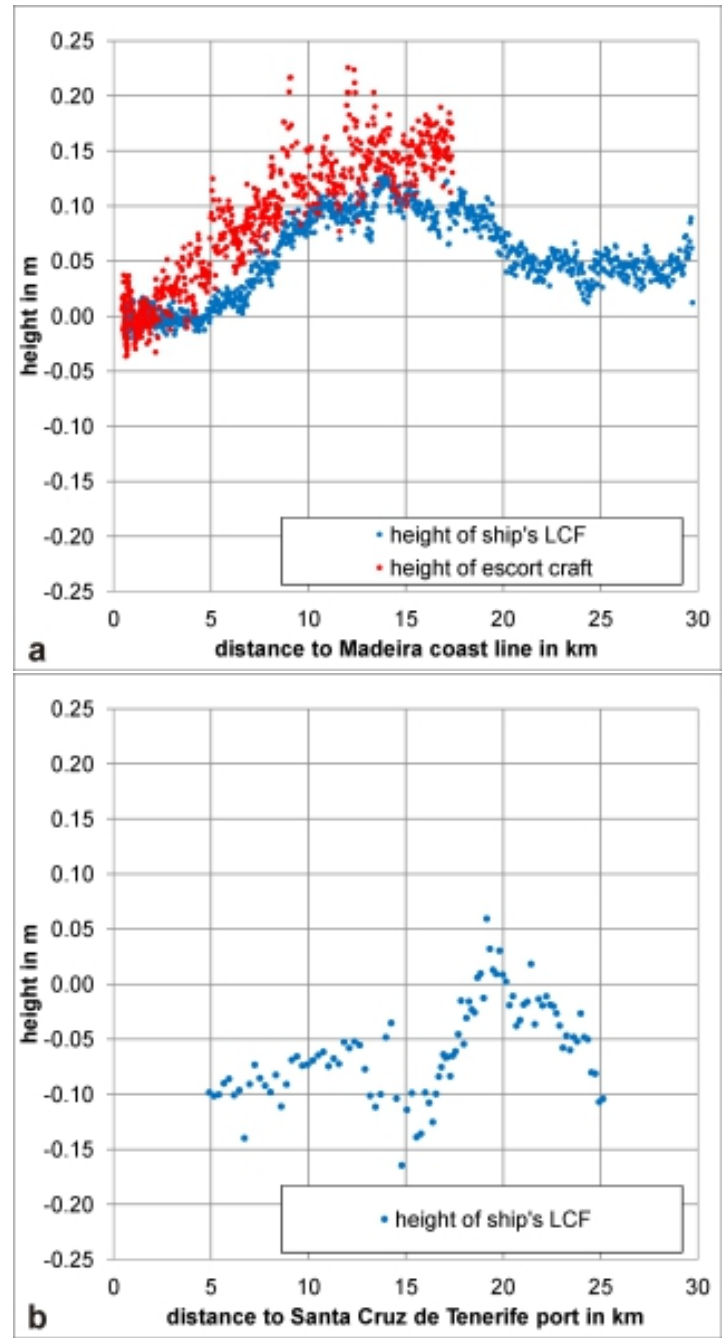

Figure 16. Heights of LCF and escort craft's ARP at Madeira (a) and LCF height at Tenerife (b) with respect to static heights.

ficients. The factor for the AIDAblu agrees perfectly with those from the CFD calculations.

\subsection{Instantaneous SSH}

The resulting height of the LCF obtained from the PPP solution and reduced for gross errors and outliers is now used to derive the instantaneous sea surface height along the track of the cruise vessel. Fig. 22 shows the LCF height in IGS08. It is clear that this result is influenced by a heave of the ship of up to $1 \mathrm{~m}$. The heavecorrected LCF height shows a much lower dispersion but it is still influenced by the squat of the ship. This was corrected for by the derived squat function. The resulting LCF height represents the sea surface height including tidal variations and changes of geoid heights along the vessel's track. In analogy to Bouin et al. (2009) we calculated the short period precision (SPP) for which we com-

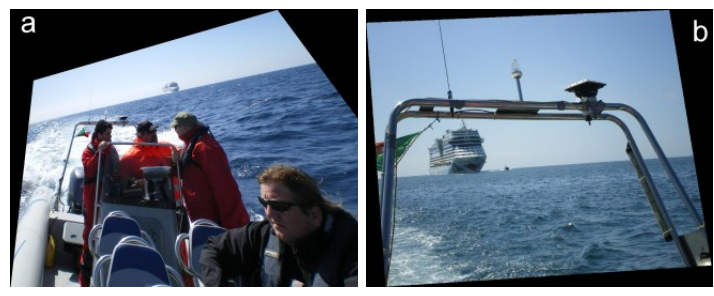

Figure 17. Rectified photos taken aboard the escort craft during the cruise (a) and after pilot boarding (b) used to estimate the heel influence on the antenna height.

puted the standard deviation of the mean value of the derived SSH over an interval with a length of $500 \mathrm{~m}$. Although the correct elimination of long-periodic systematic effects (e.g. the ship's squat) cannot be controlled by SPP, this value gives an acceptable indicator for the noise level of the data. The histogram of the SPP values is shown in Fig. 23, where the average SPP is $1.9 \mathrm{~cm}$ with a maximum value of $8.1 \mathrm{~cm}$. The LCF heights were reduced by the geoid heights from EIGEN-6C, the tidal variation from DTU10 including ocean tides and ocean tide loading. Additionally, a correction for the Inverse Barometer effect was applied according to Picot et al. (2003) for which the pressure at the position of the ship was taken from the VDR data set. The result is plotted in Fig. 24. For comparison the LCF heights without squat correction are displayed. It can clearly be seen that the disregard of the hydrodynamic behaviour of the ship would produce incorrect results which lead to misinterpretation of SSH and sea level anomalies.

\section{Conclusion}

We demonstrated that ship-based GNSS measurements can be used for precise observation of SSH if appropriate corrections are taken into account. Apart from static corrections, which directly influence the draft of a vessel and hence the antenna height above the sea level, additional hydrodynamic corrections must be considered, in particular the squat of a ship, as well as corrections related to ocean dynamics. These hydrodynamic corrections can be determined with high precision for small craft as well as for seagoing ships. Because a ship's squat depends not only on speed but also on the water depth, larger vessels are more suitable for surveys of SSH in the open ocean and offshore where the water depth is certainly larger than the depth of influence. Smaller craft, which are often used for hydrographic or scientific purposes in coastal waters, are more appropriate there. Though, a speed depending height change of GNSS antennas must be considered, which can reach values of $25 \mathrm{~cm}$ and more. The determination of antenna heights from GNSS observations limits the precision of ship-based SSH measurements. In coastal waters fixed reference stations can be used to derive relative coordinates with the typical precision of kinematic GNSS processing. Nowadays, PPP processing gives good possibilities to derive absolute heights in the open ocean with a quality of better than $5 \mathrm{~cm}$, also for kinematic applications. It has 

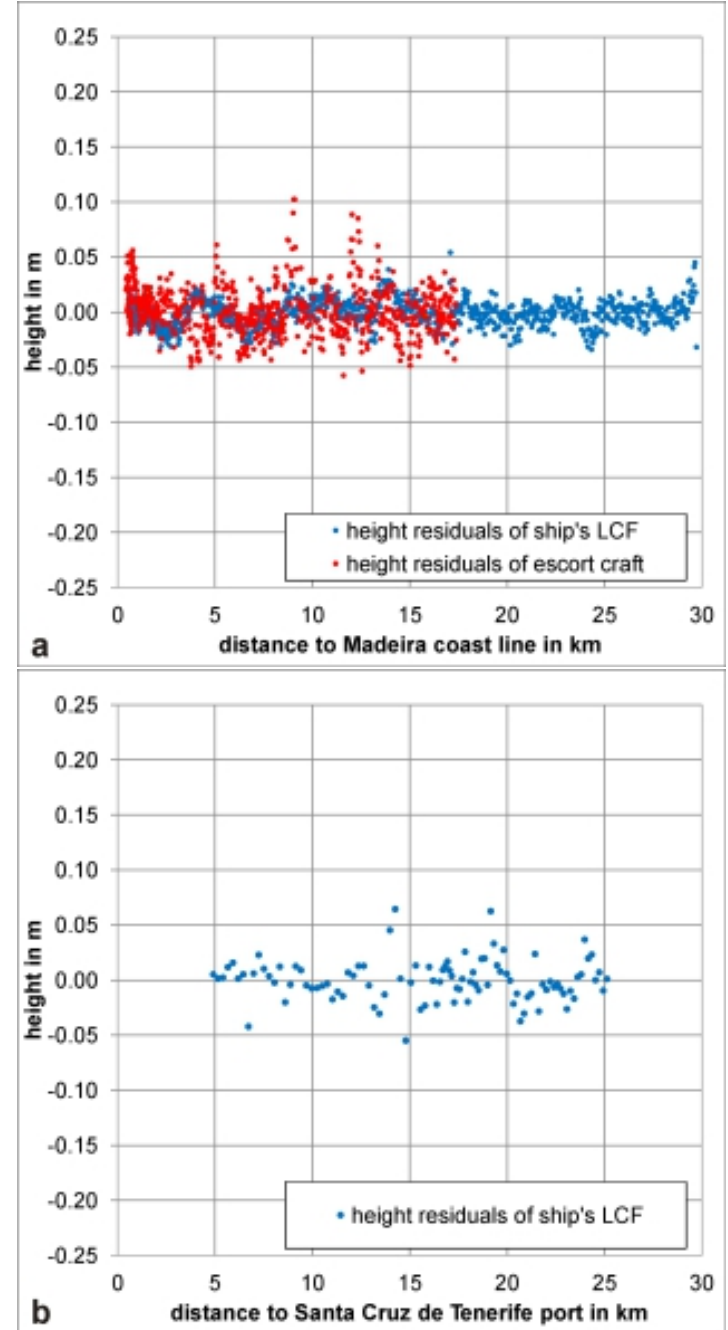

Figure 18. Height residuals of LCF and escort craft's ARP at Madeira (a) and LCF height at Tenerife (b) from common adjustment.

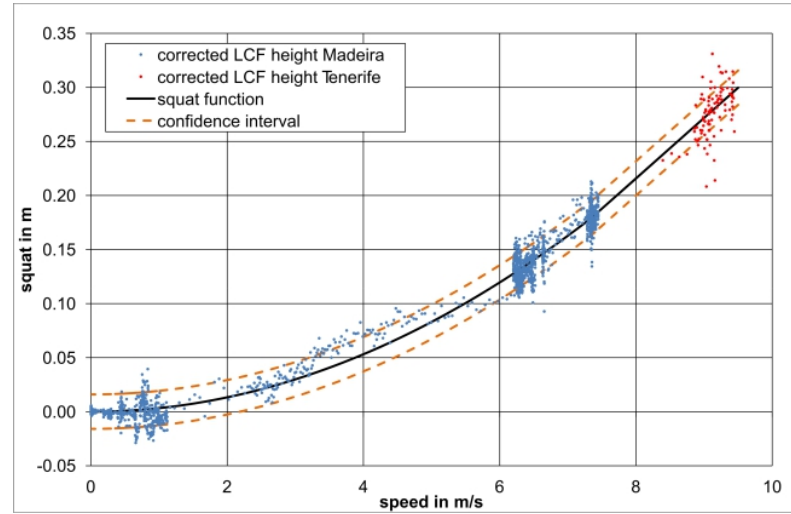

Figure 19. Corrected heights of LCF with respect to static heights, resulting quadratic squat function and related confidence interval.

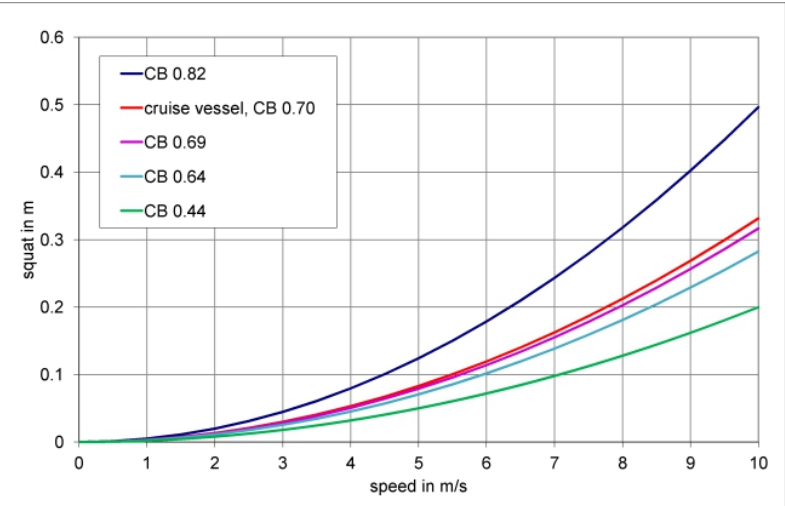

Figure 20. Squat functions for the cruise vessel derived from this experiment and for ships with different block coefficients CB calculated by means of CFD.

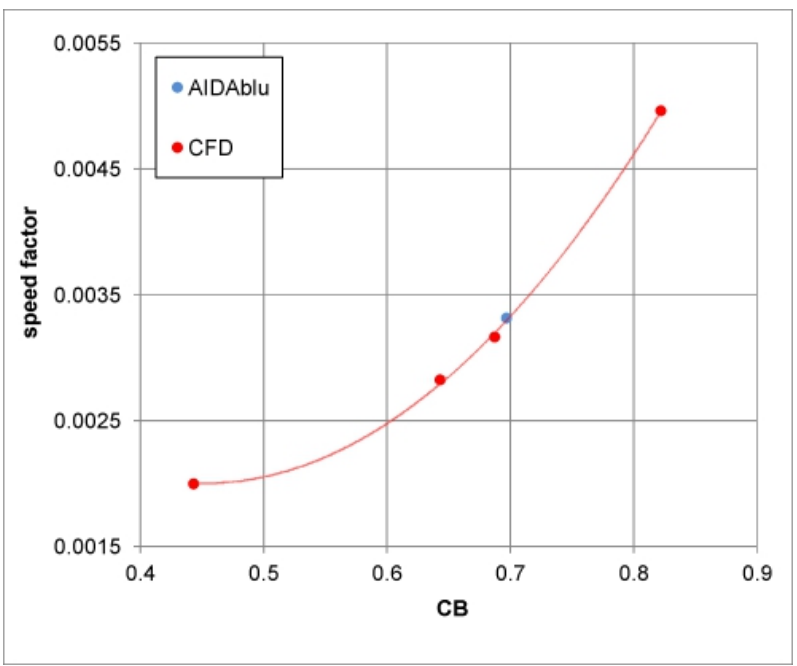

Figure 21. Speed factors of squat functions from CFD calculations and for the cruise vessel AIDAblu from this investigation.

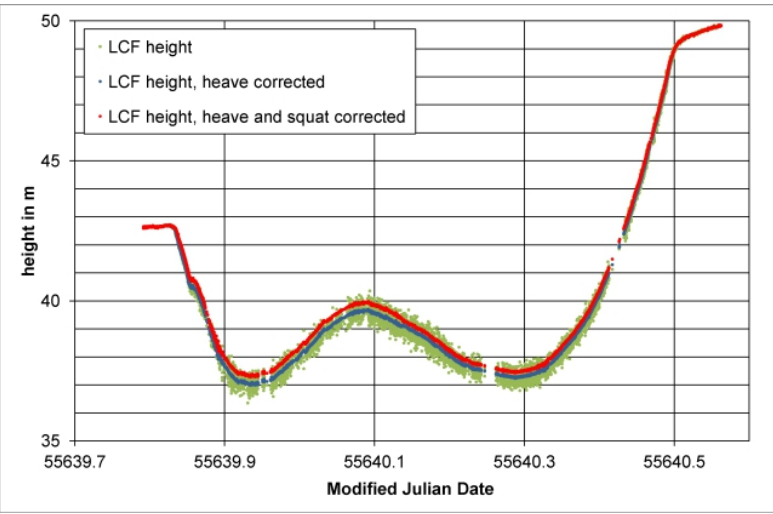

Figure 22. LCF height between Tenerife and Madeira along the track of the cruise vessel. The fully corrected LCF height represents the instantaneous $\mathrm{SHH}$. 


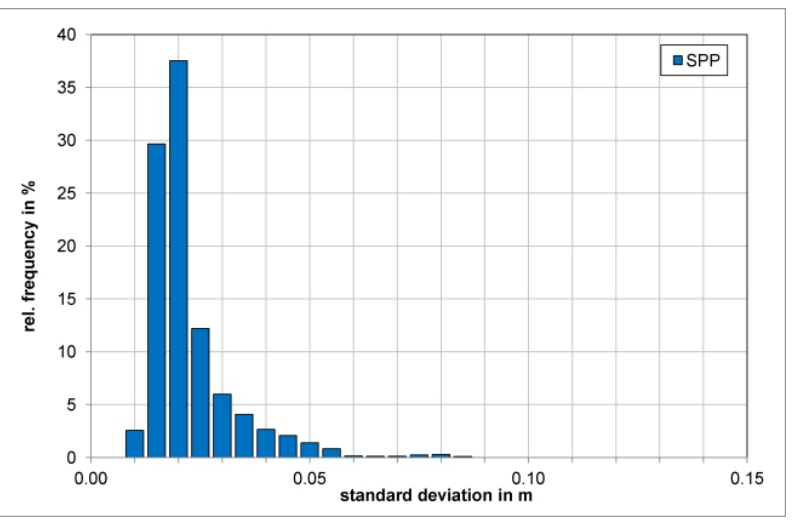

Figure 23. Histogram of short period precision (SPP) of LCF height calculated over intervals of length $500 \mathrm{~m}$ along the track of the cruise vessel.

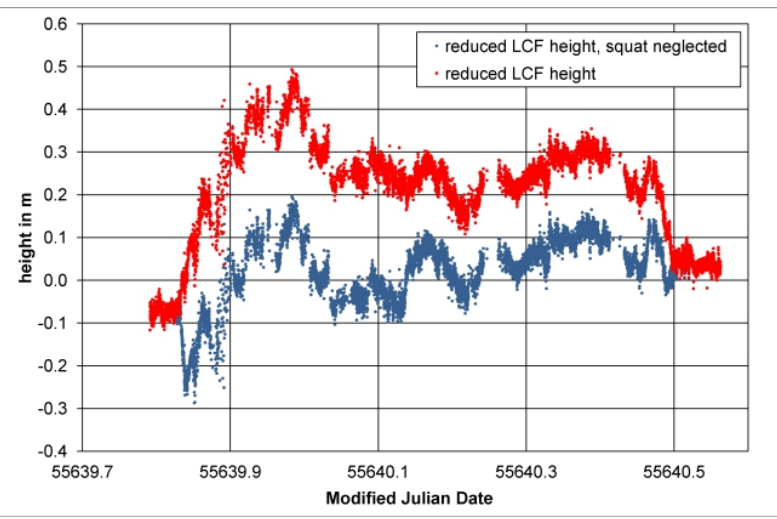

Figure 24. LCF height reduced by geoid heights, tidal variation, ocean loading and Inverse Barometer with and without squat correction.

proven reasonable to use multiple GNSS receivers aboard a ship to derive highly precise relative coordinate differences, which can be used for blunder detection and the elimination of gross errors. The quality of the results was only estimated using standard deviations or differences of results. An extensive analysis would be possible and necessary to build a complex uncertainty model which should also include correlations between the applied corrections and the resulting parameters. Due to the complexity of the problem a full description would go beyond the limits of this article and should therefore be the subject of another publication. It is foreseeable that future developments in PPP processing will lead to increased quality and reliability of the PPP results. Therefore, ship-based observations of SSH will be a significant complement to existing remote sensing methods. It is conceivable to equip a larger fleet of seagoing ships with GNSS receivers and process and analyze the data in a scientific community similar to the IGS. The derived information would likewise emphasize the reliability of the results from remote sensing methods. The data set with the results of the presented case study can be accessed upon e-mail request to the authors.

\section{Acknowledgments}

This work has been supported in part by Volkswagenstiftung (grant number ZN2172) and Jade University of Applied Sciences. We would like to thank the crew of AIDAblu and Oceanodroma for their excellent support during this campaign. Special thanks are due to Emilio Vélez (Instituto de Astronomía y Geodesia, University of Madrid) for providing GNSS and tide gauge data from the Canary Islands. Rui Caldera from CIIMAR-Madeira supported us with logistic help and tide gauge data from Funchal. Particular thanks go to Paulo Mareiros from Instituto Hidrográfico, Portugal for his persistent and successful efforts to provide detailed tide gauge data from Funchal. We thank Anne Laupichler for help with CFD calculations, Tobias Berndt for logistic support and data evaluation and Heid Hastedt for the projective rectification of digital images.

\section{References}

Barras C., 2004, Thirty-two years of Research into Ship Squat, Elsflether Schriften zur Seeverkehrs- und Hafenwirtschaft, 3, $1-25$.

Barthelmes F., 2009, Definition of functionals of the geopotential and their calculation from spherical harmonic models: theory and formulas used by the calculation service of the International Centre for Global Earth Models (ICGEM), Scientific Technical Report 09/02, GFZ, 32, DOI: 10.2312/GFZ.b10309026.

Bonnefond P., Exertier P., Laurain O., Ménard Y., Orsoni A., Jan G. and Jeansou E., 2003, Absolute calibration of Jason-1 and TOPEX/Poseidon altimeters in Corsica, Mar. Geod., 26, 261-284.

Bosch W. and Savcenko R., 2010, On estimating the dynamic ocean topography, In: Mertikas S.P. (Ed.): Gravity, Geoid and Earth Observation, Springer IAG Symposia, 135, 263-269.

Bouin M.-N., Ballu V., Calmant S., Boré J.-M., Folcher E.and Ammann J., 2009, A kinematic GPS methodology for sea surface mapping, Vanuatu, J Geod., 83, 1203-1217.

Chang X.-W., Yang X. and Zhou T., 2005, MLAMBDA: a modified LAMBDA method for integer least-squares estimation, J Geod., 79, 552-565.

Cheng Y. and Andersen O. B., 2010, Improvement in global ocean tide model in shallow water regions, Poster, SV.1-68 45, 
OSTST, Lisbon, Oct.18-22, improvement in global ocean tide model in shallow water regions, accessed 05 December 2011.

Dach R., Brockmann E., Schaer S., Beutler G., Meindl M., Prange L., Bock H., Jággi A. and Ostini L., 2009, GNSS processing at CODE: status report, J Geod., 83, 353-365.

Eriksen T., Skauen A. N., Narheim B., Helleren O., Olsen O. and Olsen R. B., 2010, Tracking ship traffic with space-based AIS: experience gained in first months of operations, proceedings 2nd International Waterside Security Conference, ISBN 978-1-4244-8894-0, DOI:10.1109/WSSC.2010.5730241.

Foster J. H., Carter G. S. and Merrifield M. A., 2009, Shipbased measurements of sea surface topography, Geophys. Res. Lett., 36, L11605, DOI:10.1029/2009GL038324.

Fórste C., Bruinsma S., Shako R., Marty J.-C., Flechtner F., Abrikosov O., Dahle C., Lemoine J.- M., Neumayer K. H., Biancale R., Barthelmes F., Kónig R. and Balmino G., 2011, EIGEN-6 - A new combined global gravity field model including GOCE data from the collaboration of GFZ-Potsdam and GRGS-Toulouse, Geophys. Res. Abstr.,13, EGU2011-3242-2.

Franke R., Hagen H. and Nielson G. M., 1994, Least squares surface approximation to scattered data using multiquadratic functions, Adv. Comput. Math., 2, 81-99.

Geng J., Teferle F. N., Meng X. and Dodson A. H., 2010, Kinematic precise point positioning at remote marine platforms, GPS Solut., 14, 343-350.

Hárting A. and Reinking J., 2002, SHIPS: A new method for efficient full-scale ship squat determination, proc. PIANC congress Sydney 2002, 1805-1813.

Hárting A., Berndt T. and Reinking J., 2007, Squat related effects on small surveying craft, proc. Hydrogr. Tech. Aware. Seminar: Cape Town 2007 / Hydrographic Society of South Africa.

Hárting A., Reinking J., Ellmer W., 2004 Ship Squat in Hydrography- a study of the surveying vessel Deneb. Int.Hydrogr. Rev., Vol. 5 No. 3.

Hugentobler U., Dach R., Fridez P. and Meindl M. (eds), 2006, Bernese GPS software version 5.0 Draft. Astronomical Institute University of Berne, pp 574.

Lagerloef G., Colomb F. R., Le Vine D., Wentz F., Yueh S., Ruf C., Lilly J., Gunn J., Chao Y., deCharon A., Feldman G. and Swift C., 2008, The Aquarius/SAC-D Mission: Designed to Meet the Salinity Remote-Sensing Challenge. Oceanography 21-1, pp. 68-81.

Parks T. W. and Burrus C. S., 1987, Digital filter design, John Wiley and Sons, New York.

Petit G. and Luzum B. (eds.), 2010, IERS Conventions, IERS Technical Note No. 36. Frankfurt am Main: Verlag des Bundesamts für Kartographie und Geodesie, ISBN: 3-89888-989-6.

Picot N., Case K., Desai S. and Vincent P., 2003, Aviso and PoDaac User Handbook - IGDR and GDR Jason-1 Product, SMM-MU-M5-OP-13184-CN (AVISO), JPL D-21352 (PODAAC)

Pineau-Guillou L. and Dorst L. L., 2011, Creation of vertical reference surfaces at sea using altimetry and GPS, Ann. Hydrograph., 8, 777,10, http://www.shom.fr/fr_page/fr_prod_annales/777/777-

ZTL.pdf, accessed 24 April 2012

Plag H.-P., Rizos C., Rothacher M. and Neiland R., 2010, The global geodetic observing system (GGOS): detecting the fingerprints of global change in geodetic quantities, In: Chuvieco, E., Li J., Yang X. (Eds): Advances in Earth Observation of Global Change edited by E. Chuvieco, J. Li and X. Yang, X., Springer Netherlands, 1st Edition, 125-144.

Reinking J. and Hárting A., 2002, Heave determination by stand-alone GPS and/or inertial sensors, Proc. Hydro 2002, Kiel, 452-459.

Reinking J. and Hárting A., 2007, Geodetic contributions to ship dynamics, PositionIT online November/December 2007, EE Publishers, Muldersdrift, South Africa, 18-23.

Reinking J., Laupichler A. and Hárting A., 2009, On the dynamic trim of container ships, Elsflether Schriften zur Seeverkehrs- und Hafenwirtschaft, 4, 88-99.

Reinking J., 2010, Marine Geodesy, In: Science of Geodesy, Xu, G. (Ed.), Springer, Berlin, ISBN: 3642117406, 275-299.

Semmling A. M., Beyerle G., Stosius R., Dick G., Wickert J., Fabra F., Cardellach E., Ribó S., Rius A., Helm A., Yudanov S. B. and d'Addio S., 2011, Detection of Arctic Ocean tides using interferometric GNSS-R signals, Geophys. Res. Lett., 38, L04103.

Schóne T., Forberg M., Galas R. and Reigber C., 2002, GPS buoys for lifetime RA drift monitoring. In: AGU Fall Meeting, EOS Trans., AGU, 83, 47, Fall Meet. Suppl., Abs. 0S52A-0189.

Shum C., Yi Y., Cheng K., Kuo C., Braun A., Calmant S. and 


\section{Journal of Geodetic Science}

Chambers D., 2003, Calibration of Jason-1 Altimeter over Lake Erie, Mar. Geod., 26, 335-354.

Teferle F. N., Orliac E. J. and Bingley R. M., 2007, An assessment of Bernese GPS software precise point positioning using IGS final products for global site velocities, GPS Solut., $11,205-213$.

Van Dorn W., 1993, Oceanography and Seamanship, Cornell Maritime Press; 2nd edition.
Watson C., Coleman R., White N., Church J. and Govind R., 2003, Absolute calibration of TOPEX/Poseidon and Jason-1 using GPS buoys in bass strait, Austral. Mar. Geod., 26, 285-304.

Wigley W. C. 5., 1926, Ship wave resistance, a comparison of mathematical theory with experimental Results, Trans. Inst. Nav. Arch., 68, 124-137. 